\title{
KESALAHAN YANG DILAKUKAN SISWA PADA PENGGUNAAN BENTUK PAST TENSE DALAM MENULIS RECOUNT TEXT
}

\author{
Rahmati \\ STMIK Bina Bangsa Lhokseumawe \\ Korespondensi: Zakimaimun87@gmail.com
}

\begin{abstract}
Abstrak: Penelitian ini bertujuan untuk mengungkapkan jenis kesalahan dalam penggunaan tense(bentuk waktu) past tense yang dibuat oleh siswa kelas satu SMA Negeri 2 Lhokseumawe. Dalam menulis kalimat, para siswa diminta untuk menulis bebas tentang pengalaman mereka ketika liburan. Selain itu, penelitian ini juga memberikan identifikasi dan penjelasan dari jenis kesalahan untuk mengetahui jenis kesalahan yang sering dilakukan. Sampel penelitian ini adalah semua siswa kelas X-4 SMA Negeri 2 Lhokseumawe dengan jumlah siswa sebanyak 32. Dalam penelitian ini penulis menerapkan teori error analysis dari beberapa buku dan referensi yang berhubungan dengan analisis kesalahan dan tata bahasa dan juga memberikan tes untuk mengumpulkan data penelitian. Kemudian data dianalisa untuk menentukan kesalahan tata bahasa dari kalimat yang menandainya, merekonstruksi kalimat tersebut, menganalis kalimat yang memiliki kesalahan, mengelompokkan jenis kesalahan, dan menghitung setiap jenis kesalahan untuk mengetahui jenis kesalahan mana yang paling sering dibuat oleh siswa. Data menunjukkan bahwa siswa yang melakukan kesalahan pada Omission sebanyak 64 kesalahan, Addition 29 kesalahan, misformation sebanyak 83 kesalahan.dengan persentase kesalahan pada bagian orientation sebanyak 61 (35\%), pada bagian Events sebanyak $82(46 \%)$, dan pada bagian reorientation sebanyak 23(19\%). Berdasarkan hasil penelitian, penulis menyarankan bahwa siswa harus lebih fokus dalam memahami penggunaan past tense khususnya pada perubahan bentuk kata kerja baik dalam bentuk kata kerja yang beraturan dan tidak beraturan, dan juga dalam penggunaan kata kerja bantu (Auxiliaries). Selain itu, guru juga perlu mengetahui bahwa siswa masih mengalami kesulitan dalam hal perubahan kata kerja pada bentuk past tense, dan dapat menerapkan metode baru.
\end{abstract}

Kata Kunci: Recount text, Schematic Structure, Errors Analysis 


\section{STUDENTS' ERRORS ON THE USE OF PAST TENSE IN RECOUNT TEXT}

Abstract: The objective of the study is to reveal the errors in using past tense for recount text made by the first year students of SMA Negeri 2 Lhokseumawe through free writing. The students were asked to write about their experience on the holiday. Furthermore, it attempts to give identification and description of the types of errors based on Surface Strategy Taxonomy and then to find out the kind of frequently encountered errors. In this study, the errors were classified from each stage of recount text namely, orientation, events, and reorientation. The sample of the study is all the X-4 students of SMA Negeri 2 Lhokseumawe, numbering at 32 students. The writer applied the theories from books and references related to error analysis and grammar and administered a test to collect the data. The data were analyzed through analyzing the incorrect from of the use of past tense by marking to the errors, analyzing the errors, classifying the errors, and counting each kind of errors in order to know the most frequent types of errors. The data shows that the students encountered errors on omission 64 errors, in addition 29 errors, and the error of misformation numbered 83 errors.the categories of percentage showed that $61(35 \%)$ in orientation, $82(46 \%)$ errors in events, and $23(19 \%)$ in reorientation. In line of the result of the study, the writer suggest that the students need to learn more intensive about the use of past tense in recount text especially the change of the verb form both in regular and irregular verbs, as well as the use of auxiliary verbs. Additionally, it is essential to the teacher to know that changing the verb from is still hard for the students.

Keywords: Recount text, Schematic Structure, Errors Analysis

\section{PENDAHULUAN}

Menulis merupakan salah satu kemampuan dasar didalam bahasa inggris yang mempunyai peranan penting dalam proses belajar-mengajar. Menulis dalam bahasa inggris terdiri dari beberapa komponen yaitu spelling, grammar, vocabulary dan punctuation. Sebagaimana Braine and May (1996:60) menyatakan bahwa menulis kalimat yang jelas mengharuskan anda mempelajari aturan tata bahasa dan mekanika bahasa inggris seperti penggunaan kata kerja dan kata ganti yang benar, serta koma dan tanda lainnya. Berdasarkan kurikulum Tingkat Satuan Sekolah (KTSP), pengajaran 
menulis siswa diarahkan agar mampu menulis paragraph singkat. Teks-teks yang dianjurkan adalah recount, narasi, deskriptif, procedure dan laporan. Ada beberapa cara untuk mengatur kalimat dalam sebuah tulisan salah satunya adalah teks recount.

Teks recount adalah bentuk teks yang bertujuan menceritakan kembali pengalaman siswa pada masa lampau, penggunaan bentuk past tense menjadi sangat penting dalam menulis teks recount. Dalam hal ini kesalahan siswa banyak ditemukan ketika mereka menulis pada setiap pola umum dari teks recount yang dikenal dengan generic structure yaitu, a. Orientation, b. Events, c. Reorientation. Kemampuan siswa dalam menulis kalimat tidak sama antara satu orang dengan yang lainnya, sebagian siswa kesulitan dalam hal tata bahasanya, maka diperlukan solusi untuk mengatasi masalah tersebut agar mereka mampu menulis teks recount dengan baik. Maka dalam hal ini peneliti lebih fokus dalam menemukan kesalahan pada penggunaan verbs dalam penulisan pengalaman siswa tentang liburan.

Richards (1974:124) menyatakan:

"sumber kesalahan dalam mempelajari sebuah bahasa berasal dari gangguan pengguna bahasa ibu atau dikenal dengan istilah Interlanguage Error. Dan ciri umum kesalahan disebut dengan kesalahan dalam bahasa yang dikenal dengan istilah intralanguage errors."

Menurut Dulay et, al. (1982:150), surface taxonomy mengelompokkan kesalahan menjadi 4 kelompok yaitu: 1) Omission, 2). Addition, 3). Misformation, 4). Misordering

Berdasarkan penjelasan diatas, peneliti fokus pada kesalahan yang dilakukan siswa pada penulisan teks recount.siswa diberikan ujian menulis karangan bebas tentang liburan. Selanjutnya tulisan siswa tersebut di analisa secara detail pada penggunaan bentuk past tense pada tiap schematic structure dari teks recount. Maka, penelitian ini berkaitan dengaan pertanyaan-pertanyaan berikut ini:

1. Jenis kesalahan apa saja yang sering dilakukan oleh siswa pada teks recount?

2. Pada bagian mana saja didalam penulisan teks recount sering dilakukan kesalahan?

Berdasarkan rumusan masalah diatas, maka tujuan penelitian ini adalah:

1. Untuk mengetahui jenis kesalahan yang umum di buat oleh siswa SMA Negeri 2 Lhokseumawe. 
2. Untuk mengidentifikasi masalah pada penggunaan kata kerja dan kesalahan penulisan tensis yang sering dilakukan oleh siswa

Penelitian ini dilakukan untuk mengetahui kesalahan bentuk past tense yang dilakukan oleh siswa pada tiap bagian tahapan dari teks recount seperti orientation, events, reorientation Oleh karenanya, judul penelitiaan ini adalah "Kesalahan Yang Dilakukan Siswa Pada Penggunaan Bentuk Past Tense Dalam Menulis Recount Text”.

\section{METODE}

Penelitian ini bersifat studi kasus, dimana berdasarkan pendapat Thomas (2011): "Studi kasus merupakan jenis penelitian yang berkonsentrasi pada satu peristiwa, dan melihat peristiwa tersebut secara mendetail". Penelitian ini dilakukan pada tanggal 10 mei 2012 di SMA negeri 2 Lhokseumawe. Dimana sampel nya dilakukan terhadap 32siswa kelas satu dengan memberikan mereka ujian dalam bentuk penulisa karangan bebas tentang pengalaman mereka ketika liburan. Pengumpulan data dilakukan untuk mengetahui tingkat kesalahan yang di lakukan oleh siswa pada penulisan teks recount. Berikut tahapan yang dilakukan dalam mengolah data analisis:

\section{Mengumpulkan kesalahan}

Pada tahapan pertama tulisan siswa dikumpulkan, selanjutnya dilakukan identifikasi dan pengelompokkan berdasarkan tujuan penelitian.

2. Mengidentifikasi kesalahan

Pada tahapan ini, peneliti mencoba menemukan kesalahan bentuk past tense yang dibuat oleh siswa didalam tulisan mereka dan menganalisa data secara objektif

\section{Pembagian kesalahan}

Ketika kesalahan sudah diidentifikasi berdasarkan 4 jenis kesalahan sesuai taxonomi surface.

\section{Menghitung kesalahan}

Penghitungan lebih jauh dilakukan terhadap kesalahan yang dibuat untuk mengetahui tingkat kesalahan pada penggunaan bentuk past 
tense yang di lakukan oleh siswa kelas satu SMA Negeri 2 Lhokseumawe.

Berikut ini adalah rumus yang digunakan untuk mengetahui jumlah kesalahan siswa:

$$
P=\frac{F}{N} \times 100 \%
$$

Keterangan :

$$
\begin{aligned}
& \mathrm{P}=\text { Nilai rata-rata kesalahan } \\
& \mathrm{F}=\text { frekuensi setiap kesalahan } \\
& \mathrm{N}=\text { jumlah total seluruh kesalahan }
\end{aligned}
$$

(Anas Sidijono. 2006:205)

\section{HASIL DAN PEMBAHASAN}

Berdasarkan pembahasan sebelumnya dimana sumber data dari penelitian ini adalah penulisan siswa pada teks recount. Dimana terdapat banyak kesalahan yang dibuat oleh siswa padaa penggunaan bentuk past tense .berikut contoh analisa penulisan yang dilakukan oleh siswa kelas satu SMA Negeri 2 Lhokseumawe:

1. Last holiday me and my friends go to the zoo

2. On $14^{\text {th }}$ february 2011 in the morning he come to my house

3. It is didn't difficult to get arround

4. There is didn't bus in the evening

5. They bringed boy friend

6. Me and Dian are waked up it very morning

Berdasarkan data diatas, dapat dilihat bahwa siswa melakukan kesalahan bentuk misformation dan kesalahan pada bentuk verb pada bentuk past tense 


\begin{tabular}{|l|l|}
\hline \multicolumn{1}{|c|}{ The errors } & \multicolumn{1}{|c|}{ Correction } \\
\hline$-\begin{array}{l}\text { Last holiday me and my } \\
\text { friends go to the zoo }\end{array}$ & $-\begin{array}{l}\text { Last holiday My friend and } \\
\text { I went to the zoo }\end{array}$ \\
\hline $\begin{array}{l}\text { On } 14^{\text {th }} \text { February 2011 in } \\
\text { the morning he come to } \\
\text { my house }\end{array}$ & $\begin{array}{l}\text { On } 14^{\text {th }} \text { February } 2011 \text { in } \\
\text { the morning he came to } \\
\text { my house }\end{array}$ \\
\hline
\end{tabular}

Berikut adalah bentuk past pada kata kerja beraturan ada penambahan-ed or - $\mathrm{d}$, akan tetapi banyak dari siswa yang menambahkan ed or $-\mathrm{d}$ pada kata kerja yang tidak beraturan. Berikut adalah contoh kesalahan yang di buat oleh siswa pada penggunaan kata kerja beraturan dan kata kerja yang tidak beraturan:

\begin{tabular}{|c|cc|}
\hline \multicolumn{1}{|c|}{ The errors } & \multicolumn{1}{c|}{ Correction } \\
\hline$-\quad$ They binged boy friend & - & They brought boy friend \\
\hline$-\quad \begin{array}{l}\text { Me and Dian are woke up } \\
\text { it very morning }\end{array}$ & - & Dian and I woke up early \\
& & \\
\hline
\end{tabular}

Berdasarkan penjumlahan yang dilakukan pada tiap jenis kesalahan. Berikut tabel kesalahan yang di buat berdasarkan jenis kesalahan :

Table. Pendistribusian kesalahan

\begin{tabular}{|l|l|c|}
\hline No & \multicolumn{1}{|c|}{ Tipe Kesalahan } & Jumlah Kesalahan \\
\hline 1 & Error of Omission & 64 \\
\hline 2 & Error of Addition & 29 \\
\hline 3 & Error of Misformation & 83 \\
\hline 4 & Error of Misordering & - \\
\hline \multicolumn{2}{|c|}{ Total of Errors } & 176 \\
\hline
\end{tabular}

Berdasarkan tabel diatas dapat dikelompokkan jenis kesalahan yang dibuat siswa berdasarkan surface strategy taxonomy dimana kesalahan pada misformation berjumlah 83 kesalahan. Kesalahan terbanyak dilakukan siswa pada jenis kesalahan misformation disebabkan oleh banyaknya kesalahan bentuk penyusunan kata kerja, selanjtnya kesalahan dalam bentuk omission berjumlah 64 kesalahan, pada jenis addition terdapat 29 kesalahan. Akan tetapi kesalahan pada jenis misordering tidak ditemukan. Maka jumlah total dari semua jenis kesalahan berjumlah 176 Kesalahan. 
Maka untuk menemukan percentase masalah, penulis menggunakan rumus dibawah ini:

$$
P=\frac{F}{N} \times 100 \%
$$

Keterangan :

$$
\begin{aligned}
& \mathrm{P}=\text { Nilai rata-rata kesalahan } \\
& \mathrm{F}=\text { frekuensi setiap kesalahan } \\
& \mathrm{N}=\text { jumlah total seluruh kesalahan }
\end{aligned}
$$

Berikut penjumlahan pada tiap kesalahan berdasarkan tahapan teks recount:

1. Orientation

Kesalahan yang dilakukan siswa pada bagian orientation berjumlah 61, jumlah total kesalahan 176, maka jumlah persentasenya adalah:

$$
\begin{aligned}
& P=\frac{F}{N} \times 100 \% \\
& P=\frac{61}{176} \times 100 \%=35 \%
\end{aligned}
$$

2. Event

Kesalahan yang dilakukan siswa pada bagian events berjumlah 82, jumlah total kesalahan 176, maka jumlah persentasenya adalah:

$$
\begin{aligned}
& P=\frac{F}{N} \times 100 \% \\
& P=\frac{82}{176} \times 100 \%=46 \%
\end{aligned}
$$

3. Reorientation

Kesalahan yang dilakukan siswa pada bagian reorientation berjumlah 33, jumlah total kesalahan 176, maka jumlah persentasenya adalah:

$$
P=\frac{F}{N} \times 100 \%
$$




$$
P=\frac{33}{176} x 100 \%=19 \%
$$

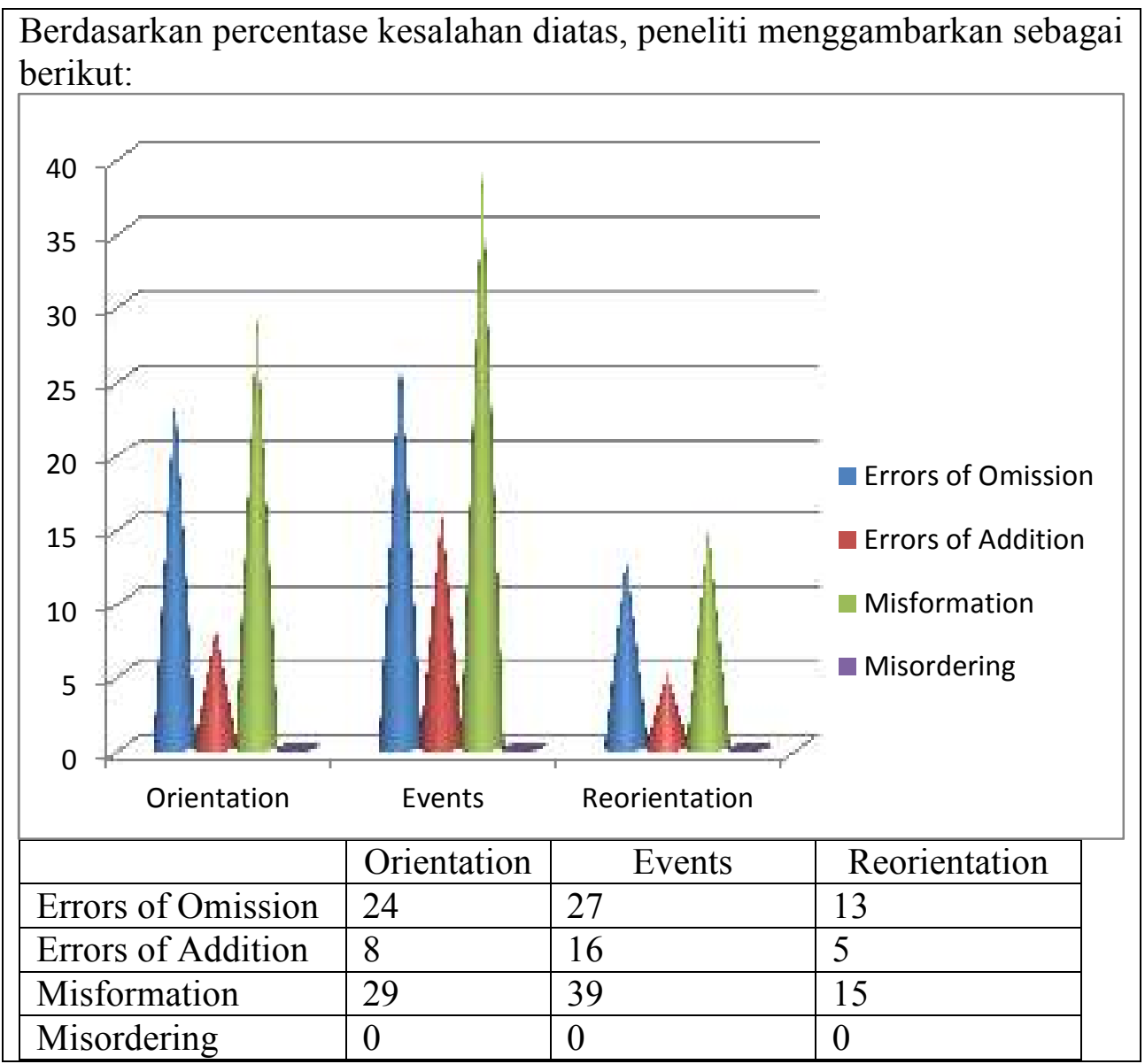

Berdasarkan gambar diatas dapat disimpulkan bahwa terdapat banyak kesalahan yang dilakukan oleh siswa berdasarkan tiap stage dalam teks recount. Pada bagian orientation, terdapat 24 kesalahan pada jenis omission, 8 kesalahan pada addition, 29 kesalahan pada misformation. Selanjutnya pada bagian events, terdapat 27 kesalahan pada jenis omission, 16 kesalahan pada addition, dan terdapat 39 kesalahan pada jenis misformation. Selanjutnya ,pada bagian reorientation terdapat kesalahan paa jenis omission sebanyak 13 kesalahan, 5 kesalahan pada jenis addition, 15 kesalahan pada jenis misformation. Akan tetapi peneliti tidak menemukan kesalahan pada jenis misordering. 


\section{PENUTUP}

Berdasarkan analisa data menunjukkan bahwa banyak siswa kelas satu SMA Negeri 2 Lhokseumawe mengalami kesulitan dalam menulis teks recount, berdasarkan analisa kesalahan disimpulkan bahwa ada 3 jenis kesalahan yang ada pada tiap-tiap tahapan menulis teks recount. Dmana terdapat 176 kesalahan yang ditemukan. Masing-masing kesalahan terdiri dari 64 kesalahan pada omission, 29 kesalahan pada addition, dan 83 kesalahan ditemukan pada jenis misformation. Adapun pada tiap-tiap tahapan menulis teks recount peneliti juga membagi kesalahan berdasarkan tahapan teks yaitu, 61 kesalahan pada bentuk orientasi, 82 kesalahan pada tahap Events dan 23 kesalahan pada tahap reorientasi. sehingga jika di persantase kan menjadi 35\% permasalahan ditemukan pada tahap orientasi, $46 \%$ permasalahan pada tahap events dan 19\% permasalahan pada reorientasi.

Berdsarkan kesimpulan diatas, peneliti menyarankan:

1. Untuk siswa; mereka harus mampu memahami dengan baik bagaimana cara menulis teks recount. Karena masih banyak siswa yang mengalami kesulitan ketika ingin menulis.

2. Untuk guru; mereka harus mampu memahami permasalahan apa saja yang dihadapi siswa dalam menulis teks recount khususnya pada penggunaan bentuk past tense sehingga mereka mampu mengulangi dengan solusi yang tepat. Harmer (1998) menyarankan tiga tahapan yang perlu diikuti oleh seorang guru ketika kesalahan terjadi, pertama, guru mendengarkan siswa, kemudian mengidentifikasi masalah dan mencari solusi dengan cara yang benar. Guru harus mampu mengubah cara berfikir siswa dalam menulis termasuk tentang penggunaan grammar dan vocabulary. Kedua, guru harus mampu menciptakan suasana kelas yang nyaman dan kondusif sehingga siswa mempunyai semangat antusias dalam proses belajarmengajar. Terakhir, guru harus mampu memberikan penjelasan lebih mendalam lagi tentang penggunaan bentuk past tense pada penulisan teks recount. 


\section{DAFTAR PUSTAKA}

Arikunto, S. 2002. Prosedure penelitian: Suatu Pendekatan Praktik. Jakarta; Rineka Cipta.

Azar, Betty S. 1999. Fundamentals of English Grammar. London : Regents/ PrentuceHall.

Brown, H.D. 2001. Teaching By Principles: An Interactive Approache To Language Pedagogy. ( $2^{\text {nd }}$ ed.). New York: Longman

Anderson, M. And K. Anderson. 1997. Text Types in English 1 and 2. South Yarra: Macmillan Education Australia pty ltd.

Azar, Betty. Schamper. 1989. Understanding and Using English Grammar. New Jersey: Prentice Hall.

Bennet. 1968. Language and Language Teaching. London: Cambridge University Press.

Brown, H. D. 2000. Principles of Language Learning and Teaching. Longman.Bungin, $\mathrm{H}$.

Byrne, Donn. 1990. Teaching Writing Skills. London and New York: Longman Group UK Limited.

Corder, S.P. 1973. Introducing Applied Linguistic. Middlesex, Penguin.

Derewianka, B. 1980. Exploring How Texts Work. Newton: Primary English Teaching Association.

Edward, E. Wilson. 2001. Writing and Grammar Communication in Action. USA: Prentice-Hall, Inc.

Eisenhardt. 1989. Building Theories from Case Study Research.

Retrieved on September, 2013, from http://ideas.repec.org/a/eee/jbrese/v64y2011i7p680-686.html.

Ellis, Rod. 2003. Second Language Acquisition: An Introductory Course. Mahwah, NJ: LEA

Gass, S. and Slinker, L. 1994. Second Language Acquisition: An Introductory Course. Mahwah, NJ: LEA.

Group.Corder, S. Pit. 1981. Error Analysis and Interlanguage. London:

Oxford University Press.

James, Carl. 1998. Errors in Language Learning and Use Exploring Error Analysis. New York: Addison Wesley Longman.

Norrish, Jhon. 1983. Language Learner and Their Errors. London: 
Macmillan Press.

Richards, J.C. 1985. The Context of Language Teaching. America:

Cambridge University Press.

Singh, Kumar Y. 2006. Fundamental of Research. Ansari Road. Daryaganj.

New Delhi. New Age International Publisher Ltd.

Smalley and Ruette. 1986. Refening Composition Skills. New York:

Macmillan Publishing Company.

Talif, R \& M, Edwin. 1989. Error Analysis of Form Four English

Compositions. The English Teacher. Vol. XVIII, September 1989.

Thomas. 2011. Qualitative Inquiry. Retrieved September, 2013, from

http://en.wikipedia.org/wiki/Case study\#History of the case study.

Thompson, A.J and Martinet, A. V. 1986. A Practical English Grammar.

New York: Oxford University Press. Text Types in English 1 and 2.

South Yarra Jan 1997

Bennet. 1968. Language and Language Teaching. London: Cambridge University Press.

James, Carl. 1998. Errors in Language Learning and Use Exploring Error Analysis. New York: Addison Wesley Longman.

Norrish, Jhon. 1983. Language Learner and Their Errors. London: Macmillan Press. 